\title{
Nonstandard Schedules and Young Children's Behavioral Outcomes Among Working Low-Income Families
}

This article focuses on how maternal employment in nonstandard schedules at night, on the weekends, or that rotate on a weekly basis influence preschoolers' behavioral outcomes. Examining low-income working mothers and their children aged $2-4$ years from the Welfare, Children, and Families: A Three-City Study $(\mathrm{N}=206)$, we find that maternal nonstandard schedules are associated with negative behavioral outcomes for young children. There is some evidence that the negative effects of nonstandard schedules on behavior problems operate indirectly through increased parenting stress. Moderating influences of child gender and family composition are also detected. These findings are consistent with the small number of studies demonstrating the negative effects of nonstandard schedules on children of varying ages.

Today in the United States, it is exceedingly common for mothers with young children to be employed. Sixty-two percent of mothers with children younger than 6 years worked in 2004

John F. Kennedy School of Government, Harvard University, 79 JFK Street, Cambridge, MA 02138 (pamela_joshi@ harvard.edu).

*Center for Survey Research, University of Massachusetts Boston, 100 Morrissey Boulevard, Boston, MA 02125.

Key Words: behavior problems, low-income families, maternal employment, nonstandard work schedules, parenting, preschoolers. compared to 39\% in 1975 (U.S. Department of Labor, Bureau of Labor Statistics, 2005). During the same time period when maternal employment increased, demand for services at night and on the weekend also expanded, leading to the creation of more service sector jobs requiring schedules outside the standard weekday workweek (Presser, 2003). Although there are numerous definitions of standard and nonstandard schedules, generally work schedules are considered to be standard if they are regularly scheduled on weekdays during the hours of 8 a.m. -6 p.m. and nonstandard if they occur primarily in the evening, at night, on the weekend, or change from week to week. Because service sector jobs that require nonstandard schedules employ a disproportionate number of mothers with young children and generally pay low wages, low-income mothers are overrepresented in these kinds of jobs with night, evening, and weekend schedules (Presser, 2003). Recent studies of mothers who left welfare for work find that high proportions of welfare leavers are employed in entry-level service and sales occupations (Holzer \& Stoll, 2001) with some analysts estimating that over $50 \%$ of these caregivers are employed on the weekends and about one quarter to one half of mothers work at night or in the early morning hours (Richer, Savner, \& Greenberg, 2001). Similarly, Presser (2003) estimates that among mothers with a low level of educational attainment, which is often associated with low socioeconomic 
status, almost $50 \%$ worked in nonstandard shifts in 1997. As record numbers of low-income mothers work in nonstandard schedules, there is a growing need to better understand how their employment schedules affect their well-being and that of their children.

Although researchers have studied the effects of increasing maternal employment on young children (Han, Waldfogel, \& Brooks-Gunn, 2001), little is known about the consequences of the timing of work schedules on these children, especially in low-income families. The majority of the studies done to date that examine the effects of nonstandard shifts on families concentrate on the direct effects on parental outcomes, whereas few consider the effects on young children. On the one hand, working nonstandard schedules may represent a family-friendly work option for higher income, dual-earner families, especially if such occupations provide greater flexibility or more discretionary time during daytime hours to spend with their young children (Garey, 1999; Presser, 2003). On the other hand, nonstandard schedules may have very different connotations for low-income parents who often work these shifts as a last resort, when jobs with standard schedules cannot be found (Dodson \& Bravo, 2005; Presser \& Cox, 1997).

We seek to address this gap in the literature by focusing on how nonstandard schedules influence preschoolers' behavioral outcomes in lowincome families. We also explore the potential indirect effects these schedules have on children through their influence on parenting stress. Lastly, we consider whether the effects of nonstandard schedules on children's behavior vary by family composition and children's gender. We investigate these questions using a sample of low-income working mothers and their children aged 2-4 years from the Welfare, Children, and Families: A Three-City Study. This article contributes to the literature by drawing on a unique data set that allows us to examine the work schedules of an understudied populationlow-income working mothers and their young children-and to study a mediating process that has not been previously considered.

\section{PREVIOUS RESEARCH AND HYPOTHESES}

Researchers are just beginning to study how nonstandard schedules affect children's development at all ages. A small number of studies find negative consequences of evening and night shifts on children's cognitive outcomes. Examining school-age children in the National Longitudinal Survey of Youth, Heymann (2000) found that parents' evening shifts increased the probability that their children score in the lowest quartile of the Peabody Individual Achievement Test of Mathematics. Focusing on children from birth to age 3 in a higher income sample, a recent large-scale longitudinal study found significant negative associations between maternal nonstandard work schedules and young children's cognitive development that were partially mediated by mothers' sensitivity to children's needs, childcare quality, and home environment (Han, 2005). There are also a limited number of studies that do not find any effects of night-shift work on children's cognitive or behavioral outcomes for school-age children in low-income families. In a cross-sectional study, Phillips (2002) found that working the night shift was not associated with positive behavior or school engagement for children aged 6 years and older in low-income families. Similarly, examining a longitudinal sample of mothers leaving welfare for work, Dunifon, Kalil, and Bajracharya (2005) found that nondaytime shifts or working at varying hours did not affect changes in school-age children's internalizing, externalizing, or positive behavioral outcomes.

These disparate findings suggest that there is a complex relationship between parental work schedules and children's outcomes that could include both costs and benefits. In terms of costs, there is a well-developed literature for workers, regardless of whether they are parents, demonstrating that nonstandard work schedules have negative effects on stress levels and decreased satisfaction with family relationships. Indeed, night- and rotating-shift schedules take their toll in the form of irregular or lack of sleep, or both (for a review, see Presser, 2003), which can contribute to fatigue and increased stress levels at home (Simon, 1990). Weekend schedules are associated with higher ratings of conflicts between balancing work and family roles (Fenwick \& Tausig, 2001). Similarly, night, rotating, and split shifts are associated with decreased family satisfaction (Grosswald, 2004) and higher levels of work-to-family spillover, which includes measures such as incidence of bad moods at home and not enough time or energy to dedicate to personal lives or family members because of jobs (Grosswald, 2003). Studies show that working outside the traditional 9 a.m. - 5 p.m. weekday schedule leads nonstandard-shift workers to be 
out of sync with family, friends, and spouses' social activities that are generally scheduled during leisure time in the evenings or on weekends (Hertz \& Charlton, 1989); being out of sync can initiate social isolation (Simon) and more marital disagreements (White \& Keith, 1990).

Studies specifically focusing on working parents also find negative effects of nonstandard work schedules. Among working parents with young children, nonstandard schedules are associated with decreased parenting satisfaction (Bogen, 2004), increased depression in the first year of parenthood (Perry-Jenkins, Goldberg, Pierce, \& Sayer, 2006), and a higher probability of divorce (Presser, 2000). Controlling for work and family characteristics, couples with children who work the evening or overnight shift have lower levels of satisfaction with parenting, including higher ratings of irritability with children and more problems attributable to children (White \& Keith, 1990). In a detailed case study of three single mothers leaving welfare for work in Milwaukee, DeParle (2004) observed that one mother working a nonstandard shift seemed to have more patience with nursing home residents during the night than that she had with her children during the day, after arriving home exhausted early in the morning. Qualitative interviews illuminate some of the reasons for lower parenting satisfaction and higher stress levels among parents working nonstandard shifts. One study of couples where fathers worked nonstandard shifts finds that mothers felt pressure to keep the children out of the house while their husbands slept during the day and that fathers felt distressed about the lack of time with their children, who were often confused about their fathers' schedules (Hertz $\&$ Charlton, 1989). Interviews with single mothers show that nonstandard work schedules are stressful because they typically cannot locate child care during the night or on weekends and they had to patch together and coordinate complex arrangements that were often unreliable (Henly \& Lambert, 2005).

Although nonstandard shifts are prevalent for low-income working parents, survey data suggest that many of these parents do not prefer to work at night, on the weekends, or on a rotating basis. Low-income and low-educated single mothers, as in our study population, are even more likely to view their nonstandard work schedules as a job requirement rather than a personal preference. Presser (2003) finds that close to $50 \%$ of low-educated single mothers between the ages of 18 and 34 years say they work in nonstandard schedules because they could not get another job, employers mandate the schedule, or it is the nature of the job. In these cases, if mothers are working in nonstandard shifts as a condition of employment rather than a preference, parenting stress and behavioral outcomes for children may increase.

The abundance of empirical evidence documenting the lack of preferences and the additional strain on parents' mental health and family relationships when working a nonstandard schedule suggests that one of the potential pathways through which nonstandard work schedules may lead to negative outcomes for children is through higher stress levels for parents. Elevated levels of parenting stress, in turn, have been linked to young children's behavior problems in several studies (Deater-Deckard, 2005). In lowincome families especially, we expect that working in nonstandard schedules may contribute to higher stress levels when trying to meet the demands of parenting roles under conditions of constrained economic resources, which could lead to higher levels of preschoolers' behavior problems.

Although there are no studies that examine the differential effects of a nonstandard schedule on boys and girls' behavior problems, we use the existing literature to consider the possible outcomes. It is well documented that preschool-aged boys are more susceptible to behavior problems than girls (Smith, Calkins, Keane, Anastopoulos, $\&$ Shelton, 2004). These differences can be explained in part by gender-specific socialization patterns such as lower levels of supervision and more independence afforded to younger boys compared to girls (Imes \& Huston, 2004). For low-income children, however, there is some indication that girls may be more susceptible to behavior problems than boys when parents go to work. Researchers studying the impact of New Hope, an antipoverty program that increased fathers and mothers' employment participation and family income, reported increased positive behaviors among boys and increased problem behaviors among girls for children of program participants compared to those in the control group (Huston et al., 2005). Ethnographic interviews with families in the program and the control groups suggest that when low-income parents went to work, they invested more resources on boys because they were afraid that they would engage in risky behaviors (Huston et al., 2003). If parents' work schedules are out of sync with their 
children's schedules as some studies suggest (Hertz \& Charlton, 1989), it may be the case that when low-income parents and children find time to spend time together, mothers and fathers invest more heavily in parenting younger boys to keep them out of trouble, which may lead to more externalizing behaviors exhibited by girls, either as a form of attention seeking or simply as a result of reduced supervision.

Although the preponderance of empirical evidence points to the overall negative effect of nonstandard shifts on children and on parenting stress, there is also a literature suggesting some positive benefits of such a schedule. Working evening or night shift may allow parents to spend time with young children who are not enrolled in school during the daytime. Similarly, working weekend shifts could allow mothers to spend time with preschoolers during weekdays. One strategy used to maximize time spent with young children and to avoid reliance on outside child-care providers is referred to as split shifts. Some parents in dual-earner families choose to synchronize nonstandard work schedules with their spouses' standard daytime or weekday schedules so that at least one parent can be available to care for children (Presser, 2003). Presser (2003) finds that over $25 \%$ of dual-earner couples worked split shifts. If mothers worked the nonstandard shift in dual-earner couples, studies find increased father involvement in preschoolers' child care (Brayfield, 1995), allowing mothers to have more time, supervision, and involvement with children during the day (Garey, 1999; Hattery, 2001). For example, Garey found that married nurses working night shifts (11 p.m. - 7:30 a.m.) were sometimes able to arrive home in the early morning and get their children ready for school or help with homework after school. Single parents also use a variation of the dual-earner split shift strategy by working nonstandard shifts in conjunction with grandmothers of their children or other relatives who care for preschoolers while they are at work. Single mothers who worked nonstandard shifts are almost twice as likely to have grandmothers or other relatives caring for their preschoolers $(88 \%)$ compared to single mothers who work standard shifts (45\%) (Presser, 2003).

The success or failure of mothers working nonstandard shifts as a strategy to benefit children is likely to depend on family composition. Research finds that low-income single mothers who work during nondaytime hours at times have to leave their children alone or with older siblings (Dodson \& Dickert, 2004) or bring their children to work (Dodson \& Bravo, 2005). Without the availability of children's fathers, other adults, or relatives to help care for children, it is likely that nonstandard shifts create a higher level of stress and complexity for single mothers managing child-care arrangements that could affect children's behavior.

Work characteristics that describe job quality, including total hours worked per week and employer benefits such as health insurance may also influence whether nonstandard work positively or negatively affects parenting and children (Kalil \& Ziol-Guest, 2005). Likewise, a number of household, maternal, and child characteristics could be important explanatory variables in considering the effect of nonstandard work on children (Han, 2005). Among the variables that must be considered are mother's age, education, race, welfare status, depression, and access to social networks; city of residence; number of children in the household; and child's age, gender, birth weight, and preterm birth status.

In sum, a limited number of studies using national samples find that parents' employment in nonstandard schedules shows negative or null effects on children. Studies of the effects of nonstandard shifts demonstrate consistent negative consequences for adults. Although clearly some preschoolers may benefit from spending more time with parents, much of these positive effects could depend on whether another parent or relative is available to spend time with them while mothers are at work. For many low-income mothers, who are likely to work in these schedules because of their availability rather than mothers' preferences for them, it is hypothesized that employment in nonstandard schedules compared to standard daytime predictable schedules, will be associated with:

(a) higher levels of children's behavior problems,

(b) more parenting stress; specifically, we postulate a mediating hypothesis whereby these elevated parenting stress levels of low-income mothers lead to higher levels of behavior problems,

(c) more acute behavior problems for children living with single parents and no other adults present in the household; that is, a moderating hypothesis that the negative effect of nonstandard work may be diminished by the presence of 
biological fathers or other adults living in the household, and

(d) higher level of behavior problems for girls compared to boys.

\section{METHOD}

\section{Data}

To test our hypotheses, we use survey data from Welfare, Children, and Families: A Three-City Study. The Three-City Study was designed to use multiple methods to learn how low-income families in Boston, Chicago, and San Antonio adapt over time to the changes brought about by the 1996 welfare reform legislation. The quantitative component of the study included a survey of 2,402 low-income families with at least one child aged $0-4$ years or $10-14$ years. The survey families were selected at random from addresses in low- and moderate-income neighborhoods. Over $90 \%$ of the block groups selected for the sample had poverty rates of $20 \%$ or more, and only households at or below $200 \%$ of the federal poverty line were eligible for interviews. We interviewed the primary female caregiver (typically the biological mother) between March and December 1999. The response rate was $74 \%$.

Referred to as the Embedded Development Study, an additional, more in-depth survey was conducted with families with children aged $2-4$ years interviewed in the main survey. This second caregiver interview addressed topics not covered in the main survey, such as the timing of work schedules, and work and family conflicts. Of the approximately 730 caregivers with children aged 2-4 years who participated in the main survey and were eligible for the Embedded Development Study survey, 626 participated, which represents an $85 \%$ response rate. Analyses comparing the characteristics of families who participated in the in-depth survey and those who did not show no significant differences in preschoolers' developmental outcomes or caregivers' demographics.

The analysis presented here is of a subsample of 206, which includes caregivers of children aged $2-4$ years who were employed at the time of both the main caregiver and the Embedded Development Study surveys. All the data used for the analysis have been weighted using sampling weights that are adjusted so that all cases from the three cities, which had slightly different sample sizes, are given equal weight. Only six caregivers were not the biological mothers of the focal children, so throughout the article we refer to caregivers as mothers.

\section{Measures}

Child behavioral outcomes. We used three scales to measure preschoolers' behavioral outcomes: internalizing problem behavior, externalizing problem behavior, and positive behavior. The internalizing and externalizing problem behavior scales are measured using two subscales from the well-established Child Behavior Checklist (Achenbach, 1991). Separate batteries of questions are asked of parents with children aged $2-3$ years and children aged $4-18$ years. The internalizing behavior problem scale consists of 25 items for 2- to 3-year-olds and 31 items for children aged 4 years and older and measures symptoms of withdrawal, somatic complaints, anxiety, and depression. The externalizing behavior problem scale (26 items for 2- to 3year-olds and 33 items for children aged 4 years or older) measures delinquent or aggressive behaviors. We summed the appropriate items for children aged $2-4$ years and then standardized scores by children's age and gender $(M=0$, $S D=1)$. Higher scores indicate more reported problem behaviors. The $\alpha$ score for the unstandardized internalizing behavior scale for 2- to 3 -year-olds is .81 and .87 for 4 -year-olds and older. The $\alpha$ score for the externalizing behavior is .90 for 2- to 3-year-olds and .89 for 4-yearolds and older, indicating high internal reliability.

Child development experts note the importance of studying both prosocial behavior as well as behavior problems (Aber \& Jones, 1997). Thus, the other child outcome measure we used is a composite of positive behaviors, which asks parents about their children's moods, sociability, and ability to empathize and calm down. This scale is composed of the mean of responses to six questions, with a higher score indicating more positive behaviors $(\alpha=.73)$.

Parenting stress. The measure of parenting stress is intended to capture how nonstandard schedules influence the everyday stress and satisfaction associated with parenting young children. Adapted from the Panel Study of Income Dynamics and the New Chance Study (Quint, Bos, \& Polit, 1997), mothers are asked seven questions relating to stress with their parenting roles such as 
whether they feel overwhelmed by parenting responsibilities and whether they feel isolated or do not have time for themselves. Mothers are also asked five questions about their satisfaction with their parenting roles such as how much satisfaction they get from parenting and whether they have the skills to be a good parent. Response categories for all items range from $1=$ strongly disagree to $5=$ strongly agree. The composite scale is composed of these 12 items asked of the caregiver $(\alpha=.71)$, and the overall score is calculated by taking the mean. A higher score indicates more perceived stress and less satisfaction with parenting.

Nonstandard schedules. The measure for nonstandard work schedule is from the Embedded Development Study component of the ThreeCity Study, which included a question about working nonstandard hours and days in the past month. The direct question asked of employed respondents is as follows: "Do you do these work activities on a regular day schedule, night or weekend shifts, split shifts, or does your schedule change week to week?" Although Presser (2003) finds that specific types of schedules can influence parent-child interactions differently, sample size limitations preclude the possibility of differentiating among the various kinds of nonstandard schedules, and so night, weekend, rotating, or split shifts were grouped together and coded as a dichotomous measure $(1=$ nonstandard schedule, $0=$ standard schedule). Indeed, a focus on distinct work schedules, which may be essential in studies of middle-class families, does not appear to capture the erratic or inconsistent routines that low-income working parents must maintain (Henly \& Lambert, 2005). A dichotomous measure therefore is more likely to reflect the actual work routines of lower skilled workers who often work an unpredictable combination of schedules at night, on the weekends, or that rotate weekly.

Other work characteristics. Highly concentrated in low-wage service occupations, jobs offering nonstandard schedules often provide minimal access to health insurance and are likely to offer a low number of work hours (Beers, 2000). Parents' work hours (Parcel \& Menaghan, 1994) and job quality indicators, including employerprovided health insurance (Kalil \& Ziol-Guest, 2005), are associated with children's behavioral outcomes. Therefore, to delineate whether the timing of work schedules is associated with child- ren's outcomes, controlling for other work characteristics, we control for mothers' work hours and employer-provided health insurance. Mothers' work hours are measured by a continuous variable that captures the total number of work hours usually worked in the week prior to the interview. Health insurance is measured by a dichotomous variable indicating whether employers provided health insurance benefits $(1=$ yes, $0=n o$ ).

Family composition and other adults' employment. Children's developmental outcomes vary significantly depending on family composition. Growing up with two biological parents is associated with children's higher socioemotional functioning compared to children living in stepfamilies or single-parent families (McLanahan \& Sandefur, 1994). For low-income families, an increasing number of studies indicate that the presence or absence of low-income fathers influences children's behavioral outcomes, although the findings are not always consistent (Coley, 2001). For low-income mothers especially, it is often the presence of another adult in the household who can help out with child supervision, which may be even more beneficial compared to living alone (Chase-Lansdale, Brooks-Gunn, \& Zamsky, 1994). Given the importance of two biological parents, we controlled for whether the focal child's biological father resided in the household and whether there were other adults living in the household who were not the biological fathers. The reference category is that no other adult lives in the household besides the mother. In all cases, biological fathers residing in the household were also married to mothers or considered to be cohabitating partners, and there were too few to separate out biological fathers by their marital status. Also, a small number of husbands or cohabitating partners were not the biological fathers of the preschool-aged focal child, but there were not enough to create a stepfather or father figure category, so we grouped them with other adults residing in the household.

If the employed mothers in our sample, whose family income is less than $200 \%$ of federal poverty guidelines, reside with the biological fathers of their children or other adults and remain low income, it could be that the other resident adults are unemployed or jobless. Mothers with young children, who need to find jobs quickly to cover the lack of earned income brought in by other adults, may disproportionately find jobs that offer 
nonstandard schedules. To disentangle the effects of mothers' work schedules, controlling for fathers' or other household members' employment participation, we include a dichotomous measure of whether any other adult in the household earned any income from wages in the month prior to the interview $(1=y e s, 0=n o)$.

Household, maternal, and child characteristics. Similar to the well-established maternal employment and child development literature (for a review, see Han et al., 2001), our models controlled for demographic and human capital characteristics such as mothers' age, race, and education. Maternal welfare receipt is negatively correlated with young children's cognitive and behavioral outcomes, but these effects dissipate when accounting for selection bias (Levine \& Zimmerman, 2005). Mothers' characteristics included in the models are race (Black and Hispanic; White is the reference category) and educational attainment (high school diploma/GED and additional education above high school; less than high school is the reference category). Mothers' welfare status is measured by two dummy variables indicating that they never received welfare $(1=y e s, 0=n o)$ or were on welfare in the past 2 years $(1=y e s, 0=n o)$; the reference category is mothers who received welfare at the time of the interview. Other household characteristics included in the models are city of residence (dummy variables for Boston and San Antonio, with Chicago as the reference category) and the number of children in the household (a continuous measure including both biological and unrelated children).

Low-income mothers' mental health characteristics such as depression and the availability of social networks are both associated directly with parenting practices and indirectly related to children's behavioral outcomes (Jackson, Brooks-Gunn, Huang, \& Glassman, 2000). We controlled for mothers' depressive symptoms using the depression subscale of the Brief Symptom Inventory (BSI 18) (Derogatis, 2000). The BSI, composed of 18 items, is used in both clinical and nonclinical settings to assess overall psychological distress, and the six-item depression subscale measures symptoms such as feelings of loneliness and hopelessness that occurred during the 7 days before the interview. We calculated the mean score of these responses, with higher scores indicating greater depressive symptoms. This scale has high internal reliability $(\alpha=.86)$. In addition, a composite measure of mothers' access to social networks was created from four questions asking about whether they have enough, too few, or no people who can help them with child care, loan money, listen to problems, or help with small favors. Higher summed scores indicated that mothers had enough people to help when they needed assistance $(\alpha=.79)$.

Demographic and health characteristics of children are also associated with differences in the development of behavior and socioemotional problems, especially in economically disadvantaged families (Ackerman, Brown, \& Izard, 2003). Child characteristics included in the models are a continuous variable measuring age in years and whether the preschool-aged focal child was male $(1=$ yes, $0=n o)$. Characteristics of children at birth, such as low weight and being born early, have been found to increase the risk of developing later health problems as well as externalizing and internalizing behavior problems over time (Hack, Klein, \& Taylor, 1995). In turn, children's health issues have been shown to influence many aspects of low-income mothers' employment such as work hours (Wolfe \& Hill, 1995) and job turnover (Earle \& Heymann, 2002) and may also influence mothers' entry into nonstandard schedules. On the basis of standard definitions of newborn health indicators (Hack et al., 1995), low birth weight is measured by a dichotomous variable indicating whether children weighed less than 5.5 pounds at birth $(1=$ yes, $0=n o)$. We measured whether the child was born preterm, 4 or more weeks early, using a dichotomous indicator $(1=$ less than 37 gestation weeks, $0=$ greater or equal to 37 gestation weeks).

\section{Modeling Strategy}

Drawing on past research concerning the effects of maternal employment on children, we tested a model of the relationship between maternal employment in nonstandard schedules and child behavior. We used ordinary least squares regression techniques to hold constant mothers' work characteristics, mothers' demographic characteristics, and household and child characteristics. To investigate Hypotheses a and b, we tested three models for each child outcome measure. First, we tested the direct effects of work schedules on children's behavioral outcomes in baseline models (Hypothesis a), holding constant 
other covariates. Second, if a statistically significant relationship is detected in baseline models between nonstandard schedules and children's behavioral outcomes, we tested for mediating effects (Hypothesis b) following the procedure outlined in Baron and Kenny (1986). In this procedure, we regressed nonstandard schedules on parenting stress, plus all baseline control variables, to test that parenting stress is significantly associated with nonstandard schedules. Third, we add parenting stress, the proposed mediating process, to the baseline models. To draw conclusions about whether parenting stress mediated the effects of nonstandard schedules, we examined the change in the magnitude and significance level of the estimated nonstandard schedule coefficient in the direct effects baseline model that did not control for parenting stress, with the estimated coefficient in the regression model that controlled for parenting stress. To test Hypotheses c and d, we included interaction terms in the final models that controlled for parenting stress to test whether children's gender, the presence of biological fathers, and the presence of other adults in the household moderated the effects of nonstandard schedules on children's behavioral outcomes.

Statistical limitations to conducting research on the effects of mothers' employment characteristics on children's developmental outcomes are inherent in this modeling strategy (Ruhm, 2004). Unmeasured characteristics can influence both mothers' entry into work schedules as well as young children's behavioral outcomes. To reduce this form of selection bias, we control for observed family and children's characteristics that have been demonstrated in prior research studies to be determinants of entry into nonstandard schedules as well as associated with children's behavioral outcomes. For example, because early childhood health problems influence mothers' employment decisions and are also determinants of behavior problems, we address this potential selection issue by controlling for measures of children's health that were present before the assessment of mothers' work schedules, such as low birth weight and preterm birth.

\section{RESULTS}

\section{Descriptive}

Table 1 presents descriptive statistics for the variables included in the regression models and shows how mothers' work, demographics, household, and children's characteristics vary by nonstandard and standard schedules. The first column of means in Table 1 shows that about three quarters of the employed mothers in the low-income sample earned a high school diploma or GED or completed some post-high school training. Nearly half of mothers were Black, and $46 \%$ were Hispanic. Most mothers were former welfare recipients (45\%) or received welfare assistance at the time of the interview (15\%). Almost $40 \%$ were never on welfare. Over one third of households included the biological father who was either married to or cohabitating with the mother, and $17 \%$ had another adult living in the household who was not the biological father. These adults were most likely to be stepfathers, boyfriends, or other relatives including grandmothers or aunts. On average, there were 2.6 children living in the household. The average age of the focal child was 3.1 years, and $48 \%$ were boys. Only $4 \%$ were born with low birth weight, and $6 \%$ were born preterm, that is, 4 or more weeks early.

Table 1 shows that $33 \%$ of our sample of lowincome working mothers of 2- to 4-year-olds is estimated to work a nonstandard schedule. Consistent with national data demonstrating fewer work hours and less health insurance coverage through employers for workers in nonstandard schedules compared to those in standard schedules (Beers, 2000), the last two columns of Table 1 show that mothers employed in jobs with nonstandard schedules worked fewer hours (29 hours) compared to those employed in jobs with standard schedules (36 hours). Also, mothers working in nonstandard schedules had less access to health insurance provided by their employers (9\%) compared to mothers working in standard schedules (35\%). Indeed, the fact that fewer than $10 \%$ of mothers working a nonstandard schedule had employer-provided health insurance compared to over one third of mothers working a standard schedule suggests that the former are in much less desirable jobs for low-income mothers. In analyses not shown, we also found that mothers working at night, on the weekends, or on a rotating basis earn significantly lower hourly wages. Whereas mothers working nonstandard schedules were likely to work in service sector occupations, mothers working standard schedules were more likely to be working in sales and administrative support occupations. These results consistently indicate that jobs with nonstandard schedules are of lower quality. 
Table 1. Descriptive Statistics for Sample of Low-Income Working Mothers With Preschoolers Broken Down by Work Schedules

\begin{tabular}{|c|c|c|c|c|}
\hline Variables & $M$ & $S D$ & Nonstandard Schedule & Standard Schedule \\
\hline \multicolumn{5}{|l|}{ Dependent variables } \\
\hline Child internalizing behavior & 0.0 & 1.0 & 0.3 & -0.2 \\
\hline Child externalizing behavior & 0.0 & 1.0 & 0.3 & -0.2 \\
\hline Child positive behavior & 4.1 & 0.7 & 4.0 & 4.2 \\
\hline Parenting stress & 2.3 & 0.6 & 2.5 & 2.2 \\
\hline \multicolumn{5}{|l|}{ Independent variables } \\
\hline Nonstandard schedule & $33.0 \%$ & & & \\
\hline \multicolumn{5}{|l|}{ Mothers' job characteristics } \\
\hline Work hours & 33.8 & 13.4 & 29.3 & 36.0 \\
\hline Employer-provided health insurance & $26.1 \%$ & & $9.1 \%$ & $34.5 \%$ \\
\hline \multicolumn{5}{|l|}{ Mothers' characteristics } \\
\hline Age & 29.0 & 6.3 & 28.7 & 29.2 \\
\hline Some/all college & $58.1 \%$ & & $60.1 \%$ & $57.1 \%$ \\
\hline High school diploma/GED & $16.2 \%$ & & $19.1 \%$ & $14.7 \%$ \\
\hline Black & $48.4 \%$ & & $44.9 \%$ & $50.2 \%$ \\
\hline Hispanic & $46.0 \%$ & & $44.5 \%$ & $46.8 \%$ \\
\hline Formerly on welfare & $45.3 \%$ & & $34.6 \%$ & $50.6 \%$ \\
\hline Never on welfare & $39.4 \%$ & & $44.2 \%$ & $37.0 \%$ \\
\hline Currently on welfare & $15.3 \%$ & & $21.2 \%$ & $12.4 \%$ \\
\hline Score on depression scale & 2.7 & 3.8 & 2.2 & 3.0 \\
\hline \multicolumn{5}{|l|}{ Household characteristics } \\
\hline Biological father reside in household & $38.1 \%$ & & $47.5 \%$ & $33.5 \%$ \\
\hline Other adults reside in household & $17.1 \%$ & & $21.6 \%$ & $14.9 \%$ \\
\hline Resident biological father or other adults are employed & $38.7 \%$ & & $46.9 \%$ & $34.7 \%$ \\
\hline Number of minors & 2.6 & 1.2 & 2.5 & 2.6 \\
\hline Social networks & 9.2 & 2.1 & 9.9 & 8.9 \\
\hline Boston & $33.3 \%$ & & $30.7 \%$ & $34.6 \%$ \\
\hline San Antonio & $33.3 \%$ & & $37.7 \%$ & $31.3 \%$ \\
\hline \multicolumn{5}{|l|}{ Focal child characteristics } \\
\hline Age in years & 3.1 & 0.8 & 3.2 & 3.0 \\
\hline Male & $47.9 \%$ & & $41.6 \%$ & $50.9 \%$ \\
\hline Low birth weight & $4.2 \%$ & & $3.4 \%$ & $4.5 \%$ \\
\hline Preterm birth & $5.8 \%$ & & $4.5 \%$ & $6.5 \%$ \\
\hline
\end{tabular}

Note: All values are weighted. $N=206$ employed mothers with preschoolers.

Examining mothers' observable human capital characteristics by work schedule (presented in the last two columns of Table 1), we see that there were only a few large differences between the mothers in our sample who worked nonstandard schedules and the mothers who worked standard schedules. In fact, mothers who worked nonstandard schedules tend to look better on key economic and social indicators. Mothers employed in jobs with nonstandard schedules had lower rates of past welfare receipt, more extensive social networks, and lower depression scores compared to mothers in standard schedules.

\section{Children's Behavioral Outcomes: Baseline and Mediator Models}

Table 2 shows the results for our tests of Hypotheses a and b. Results for Hypothesis a (Models 1, 3 , and 5) for each of the three behavioral outcomes of interest are presented in Table 2. To assess Hypothesis $b$, whether parenting stress mediates the associations between work schedules and children's behavior, we show the results of the regression models, which include all the baseline control variables and the potential mediating variable, parenting stress, in Models 2,4 , and 6 . 
Table 2. Regression Models Predicting Children's Internalizing, Externalizing, and Positive Behaviors

\begin{tabular}{|c|c|c|c|c|c|c|c|c|c|c|c|c|}
\hline \multirow[b]{3}{*}{ Variable } & \multicolumn{4}{|c|}{ Internalizing Behavior } & \multicolumn{4}{|c|}{ Externalizing Behavior } & \multicolumn{4}{|c|}{ Positive Behavior } \\
\hline & \multicolumn{2}{|c|}{ Model 1} & \multicolumn{2}{|c|}{ Model 2} & \multicolumn{2}{|c|}{ Model 3} & \multicolumn{2}{|c|}{ Model 4} & \multicolumn{2}{|c|}{ Model 5} & \multicolumn{2}{|c|}{ Model 6} \\
\hline & $b$ & $S E_{b}{ }^{\mathrm{a}}$ & $b$ & $S E_{b}$ & $b$ & $S E_{b}$ & $b$ & $S E_{b}$ & $b$ & $S E_{b}$ & $b$ & $S E_{b}$ \\
\hline \multicolumn{13}{|l|}{ Mothers' job characteristics } \\
\hline Nonstandard schedule & $0.47 *$ & 0.23 & 0.32 & 0.22 & $0.55^{* *}$ & 0.19 & $0.37 *$ & 0.17 & $-0.36 * *$ & 0.12 & $-0.27 *$ & 0.12 \\
\hline Work hours & -0.01 & 0.01 & -0.01 & 0.01 & -0.01 & 0.01 & -0.01 & 0.01 & $-0.01 * *$ & 0.01 & $-0.02 * *$ & 0.01 \\
\hline Employer-provided health insurance & 0.03 & 0.19 & 0.04 & 0.19 & 0.19 & 0.19 & 0.20 & 0.18 & 0.09 & 0.11 & 0.08 & 0.11 \\
\hline \multicolumn{13}{|l|}{ Mothers' characteristics } \\
\hline Age & -0.02 & 0.02 & -0.02 & 0.02 & 0.01 & 0.02 & 0.00 & 0.02 & -0.02 & 0.01 & -0.01 & 0.01 \\
\hline Some/all college & -0.29 & 0.24 & $-0.47 \dagger$ & 0.24 & $-0.35 \dagger$ & 0.19 & $-0.55^{* *}$ & 0.19 & 0.14 & 0.13 & $0.23 \dagger$ & 0.12 \\
\hline High school diploma/GED & -0.34 & 0.30 & -0.47 & 0.28 & $-0.39 \dagger$ & 0.23 & $-0.54 * *$ & 0.21 & -0.03 & 0.18 & 0.04 & 0.17 \\
\hline Black & 0.03 & 0.41 & -0.01 & 0.40 & 0.47 & 0.35 & 0.44 & 0.33 & 0.33 & 0.24 & 0.35 & 0.23 \\
\hline Hispanic & -0.22 & 0.37 & -0.27 & 0.36 & 0.17 & 0.31 & 0.11 & 0.28 & 0.25 & 0.24 & 0.28 & 0.23 \\
\hline Formerly on welfare & -0.02 & 0.32 & -0.03 & 0.31 & -0.07 & 0.26 & -0.08 & 0.24 & 0.20 & 0.17 & 0.21 & 0.16 \\
\hline Never on welfare & -0.02 & 0.31 & -0.13 & 0.30 & -0.15 & 0.30 & -0.28 & 0.29 & 0.30 & 0.21 & $0.37 \dagger$ & 0.20 \\
\hline Depression & 0.03 & 0.03 & 0.00 & 0.03 & $0.07 *$ & 0.03 & 0.03 & 0.03 & -0.01 & 0.02 & 0.01 & 0.02 \\
\hline \multicolumn{13}{|l|}{ Household characteristics } \\
\hline Biological father & 0.19 & 0.25 & 0.27 & 0.24 & 0.02 & 0.29 & 0.11 & 0.26 & 0.07 & 0.18 & 0.02 & 0.17 \\
\hline Other adults & -0.09 & 0.26 & -0.17 & 0.26 & -0.23 & 0.22 & -0.31 & 0.22 & 0.17 & 0.18 & 0.21 & 0.17 \\
\hline $\begin{array}{l}\text { Employment status of biological } \\
\text { father/other adults }\end{array}$ & -0.09 & 0.19 & -0.10 & 0.20 & 0.23 & 0.19 & 0.23 & 0.20 & 0.10 & 0.15 & 0.10 & 0.14 \\
\hline Number of minors & $0.22 *$ & 0.09 & $0.16 \dagger$ & 0.09 & $0.16 \dagger$ & 0.09 & 0.09 & 0.08 & $-0.07 \dagger$ & 0.04 & -0.04 & 0.05 \\
\hline Social networks & $-0.09^{*}$ & 0.04 & $-0.07 \dagger$ & 0.04 & 0.02 & 0.04 & 0.04 & 0.03 & 0.01 & 0.03 & 0.00 & 0.02 \\
\hline Boston & 0.07 & 0.24 & 0.11 & 0.22 & $0.48^{*}$ & 0.22 & $0.52 *$ & 0.20 & -0.02 & 0.15 & -0.04 & 0.14 \\
\hline San Antonio & 0.14 & 0.25 & 0.13 & 0.21 & $0.55^{*}$ & 0.24 & $0.53^{*}$ & 0.21 & 0.20 & 0.16 & 0.21 & 0.14 \\
\hline \multicolumn{13}{|l|}{ Child characteristics } \\
\hline Age in years & $0.26^{*}$ & 0.10 & $0.21 *$ & 0.09 & $0.25^{*}$ & 0.11 & $0.18 \dagger$ & 0.09 & $0.12 \dagger$ & 0.07 & $0.15^{*}$ & 0.07 \\
\hline Male & 0.01 & 0.18 & -0.15 & 0.18 & 0.14 & 0.19 & -0.05 & 0.17 & 0.15 & 0.11 & $0.24 *$ & 0.11 \\
\hline Low birth weight & 0.25 & 0.39 & 0.18 & 0.34 & 0.43 & 0.34 & 0.36 & 0.32 & -0.54 & 0.35 & -0.50 & 0.32 \\
\hline Preterm birth & -0.13 & 0.34 & -0.13 & 0.29 & -0.19 & 0.26 & -0.18 & 0.24 & $0.74 *$ & 0.30 & $0.73 * *$ & 0.26 \\
\hline Parenting stress & & & $0.57 * *$ & 0.14 & & & $0.66^{* *}$ & 0.12 & & & $-0.33 * *$ & 0.10 \\
\hline
\end{tabular}




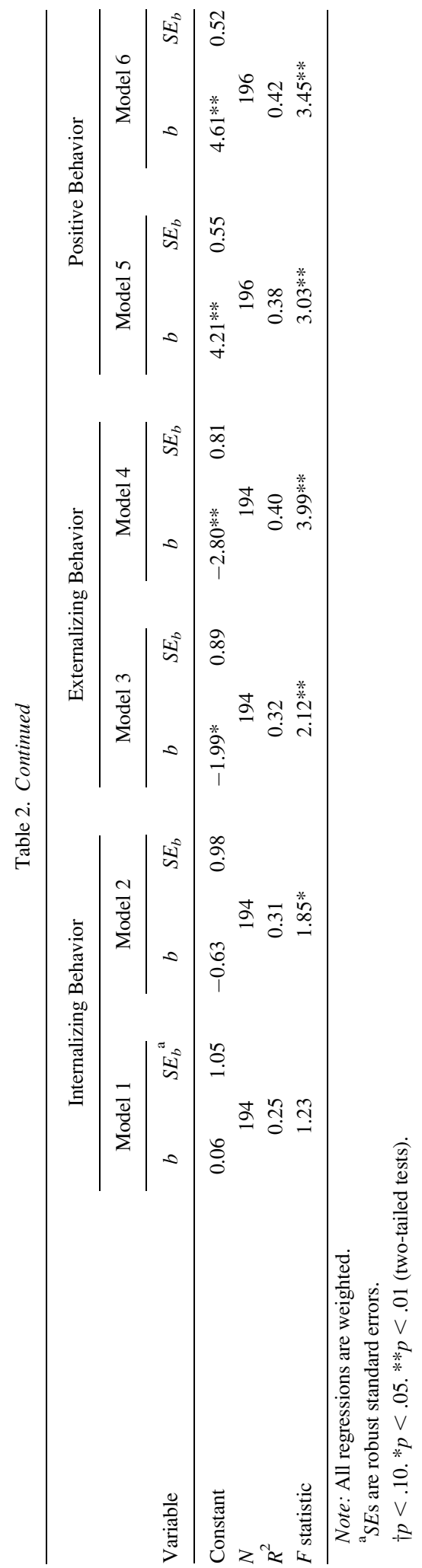

The results for Model 1 show that working in nonstandard schedules is associated with more preschoolers' internalizing behavior problems $(b=0.47, p<.05)$ in comparison to working in standard schedules. The size of the effect translates into almost one third of a standard deviation increase in internalizing behavior, which, according to conventional standards, is considered a moderate effect size (Cohen, 1988). Neither of the other two job-related measures are significantly related to internalizing behavior problems. Mothers' having more access to social networks decreases children's internalizing behavior, whereas child characteristics such as age and the number of children in the household increase internalizing behavior. Mothers' welfare status, race, education, and presence of biological fathers or other adults in the household are not significantly associated with children's internalizing behavior problems.

To assess whether the effect of nonstandard work schedules on internalizing behavior problems operates indirectly through its effects on parenting stress, we first regress parenting stress on nonstandard work schedules controlling for all covariates in the baseline model (results not shown). We find that nonstandard work schedules do significantly increase parenting stress ( $b=0.27, p<.01)$. Second, we regress internalizing behavior problems on nonstandard work schedules and other covariates including parenting stress in Model 2 and find that higher levels of parenting stress significantly increase preschoolers' internalizing behavior $(b=0.57$, $p<.01)$. In addition, examining the regression coefficients for nonstandard work schedules presented in Models 1 and 2, we see that its effect is reduced by almost one third and becomes statistically insignificant $(b=0.47$ in Model 1 compared to $b=0.32$ in Model 2). Thus, the statistically significant coefficient for nonstandard work in the parenting stress model and the reduction in the size and significance of the nonstandard work coefficient between models with (Model 2) and without parenting stress (Model 1) are considered to be evidence of a mediating role of parenting stress.

Examining the results for externalizing behavior in Table 2, Model 3 shows that compared to standard work schedules, nonstandard schedules are associated with higher reports of externalizing behaviors $(b=0.55, p<.01)$. The effect size of nonstandard schedules on preschoolers' externalizing behavior is larger than it is for 
internalizing behavior. Working in nonstandard schedules is associated with over a two-fifths standard deviation increase in externalizing behavior. Similar to internalizing behavior problems, we do not see any influence of other job characteristics on children's externalizing behavior. Compared to Chicago, children in Boston $(b=0.48, p<.05)$ and San Antonio $(b=0.55, p<.05)$ have higher reported externalizing problems. Higher levels of mothers' education contribute to lower reported externalizing problems. Also, higher levels of maternal depression $(b=0.07, p<.05)$ as well as older children $(b=0.25, p<.05)$ are associated with higher levels of externalizing behavior problems.

Next, we examine the mediating effects of parenting stress on children's externalizing behavior. We examine the reduction in the magnitude of the regression coefficients for nonstandard work in the model of externalizing behavior problems without a control variable for parenting stress (Model 3) and in the model that includes parenting stress (Model 4). The coefficient for nonstandard work in Model $3(b=0.55, p<$ $.01)$ is reduced by one third in Model 4 and becomes less statistically significant $(b=0.37$, $p<.05$ ), and parenting stress is statistically significant in Model $4(b=0.66, p<.01)$ and in the expected direction. Therefore, it is likely that the negative effect of nonstandard work on children's externalizing behavior problems is partially indirect and operates through its negative effects on increased parenting stress.

Model 5 in Table 2 shows that working in nonstandard work schedules is associated with less reported positive behavior for preschoolers compared to working in standard work schedules $(b=-0.36, p<.01)$. The magnitude of the effect of nonstandard work schedules is over two fifths of a standard deviation reduction in positive behavior. Similar to nonstandard work schedules, more work hours are associated with lower reported positive behavior, although the size of the effect is smaller $(b=-0.01, p<$ $.01)$. No other demographic characteristics of mothers are associated with children's positive behaviors. More children in the household reduces positive behaviors $(b=-0.07, p<.10)$, and the older the child is, the more likely the mothers rate better child behaviors $(b=0.12$, $p<.10)$. Children who are born preterm have higher reported levels of positive behavior $(b=$ $0.74, p<.05)$.
The results presented in Models 5 and 6 also point to a mediating effect of parenting stress on preschooler's positive behavior. Parenting stress in Model 6 is statistically significant in the expected direction $(b=-0.33, p<.01)$, and the coefficient for nonstandard work in Model $5(b=-0.36, p<.01)$ is reduced by over one third in Model $6(b=-0.27, p<.05)$ and remains statistically significant, although at a lower level. Thus, for two measures of children's behavior, externalizing and positive behaviors, these results suggest that nonstandard schedules have both a direct association with children's socioemotional development as well as an indirect association through parenting stress. The effect of nonstandard schedules on children's internalizing behavior problems is indirect, operating through parenting stress.

Initial models also controlled for other indicators of mothers' working conditions such as occupations and industries, which are the primary determinants of whether mothers work in nonstandard schedules (Presser, 2003). To obtain the most parsimonious specification of the regression models, these variables were excluded from the final models. We used Wald tests to assess the joint contribution of occupation and industry categories both separately and together and found that the combination of these variables was not statistically significant. Removing these control variables did slightly reduce the magnitude of the effects of nonstandard schedules but not the statistical significance levels.

\section{Moderating Effects}

To test whether the negative relationship between nonstandard schedules and children's behavioral outcomes is mitigated by the presence of other adults living in the household (Hypothesis c), we added two interaction terms to the models: nonstandard schedule and presence of biological fathers, and nonstandard schedule and presence of other adult besides biological fathers in the household. We find that the negative effect of nonstandard schedules on preschoolers' behavior is moderated by other adults living in the household only when the outcome is internalizing behavior. Table 3 shows the statistically significant interaction terms derived from regression models that include all baseline characteristics, parenting stress, and interaction variables. Model 7 shows that the negative effect of nonstandard schedules on children's internalizing behavior 
Table 3. Regression Models Predicting Preschoolers' Internalizing and Externalizing Behaviors Including Interaction Terms

\begin{tabular}{|c|c|c|c|c|}
\hline \multirow[b]{3}{*}{ Variable } & \multirow{2}{*}{\multicolumn{2}{|c|}{$\begin{array}{c}\text { Internalizing Behavior } \\
\text { Model } 7\end{array}$}} & \multirow{2}{*}{\multicolumn{2}{|c|}{$\frac{\text { Externalizing Behavior }}{\text { Model } 8}$}} \\
\hline & & & & \\
\hline & $b$ & $S E_{b}{ }^{\mathrm{a}}$ & $b$ & $S E_{b}$ \\
\hline \multicolumn{5}{|c|}{ Family composition $\times$ Nonstandard schedule interaction model } \\
\hline Nonstandard schedule & 0.74 & 0.48 & & \\
\hline Biological father resides in the household & $0.43 \dagger$ & 0.25 & & \\
\hline Other adult resides in the household & 0.30 & 0.34 & & \\
\hline Nonstandard schedule $\times$ Other adult & $-1.18 \dagger$ & 0.66 & & \\
\hline Nonstandard schedule $\times$ Biological father & -0.47 & 0.55 & & \\
\hline Parenting stress & $0.57 * *$ & 0.15 & & \\
\hline$N$ & \multicolumn{2}{|c|}{194} & & \\
\hline$R^{2}$ & \multicolumn{2}{|c|}{0.35} & & \\
\hline$F$ statistic & \multicolumn{2}{|c|}{$2.39 * *$} & & \\
\hline \multicolumn{5}{|c|}{ Child is male $\times$ Nonstandard schedule interaction model } \\
\hline Nonstandard schedule & & & $0.70 *$ & 0.31 \\
\hline Child is male & & & 0.12 & 0.20 \\
\hline Child is male $\times$ Nonstandard schedule & & & $-0.63 \dagger$ & 0.37 \\
\hline Parenting stress & & & $0.60 * *$ & 0.13 \\
\hline$N$ & & & \multicolumn{2}{|c|}{194} \\
\hline$R^{2}$ & & & \multicolumn{2}{|c|}{0.42} \\
\hline$F$ statistic & & & \multicolumn{2}{|c|}{$4.24 * *$} \\
\hline
\end{tabular}

problems is lower when other adults reside with children $(b=-1.18, p<.10)$. Estimating the regression models separately by family composition (biological mother only, two biological parents, and single mother living with other adults), we find that mothers' nonstandard schedules are associated with more internalizing behavior when mothers live alone or when biological fathers live in the household and are associated with less internalizing behavior when other adults live in the household (results not shown). We find no significant interaction effects in the models for externalizing problems and positive behavior outcomes.

To examine whether the negative effects of mothers' nonstandard schedules varied by children's gender (Hypothesis d), we added an interaction variable, nonstandard schedule and child is male, to our baseline model including a control variable for parenting stress. We find that child's gender only matters when examining externalizing behavior. Model 8 in Table 3, shows that although nonstandard work is associated with more externalizing behavior for both boys and girls in low-income families, the effect of nonstandard schedules is much higher for girls than for boys $(b=-0.63, p<.10)$.

\section{DISCUSSION}

As the growth of nonstandard work schedules continues throughout the economy (Beers, 2000), it is increasingly of interest how parents at all income levels manage to spend time with young children and work during the night or on weekends, which traditionally has been considered family time. A number of studies detail the negative effects of these work schedules on workers' health, work and family satisfaction, and marriages (see Presser, 2003, for a review). More recently, a limited number of quantitative studies have examined the effects of parents' work schedules on children's developmental outcomes. The results of our analyses suggest detrimental effects of nonstandard work schedules on young children's behavior. Multivariate models 
controlling for a variety of work and family characteristics (Hypothesis a) demonstrate that young children whose mothers work a nonstandard schedule compared to those working a standard schedule, show more externalizing behavior problems and fewer reported positive behaviors. In addition, the mothers themselves report more parenting stress. Our findings for Hypothesis b suggest that the negative effects of nonstandard schedules on children's externalizing and positive behaviors operate in part by increasing parents' stress levels. For internalizing behavior, the negative effects of nonstandard schedules are fully mediated by parenting stress. These findings reinforce results from the only other study of work schedules on young children, which found that the negative effects of maternal nonstandard work schedules on children's cognitive outcomes were mediated by different family processes (Han, 2005).

Examining the results for our Hypothesis c, we find that the presence of other resident adults in the household helps to mitigate the effect of mothers' nonstandard schedules by reducing internalizing behavior. In single-mother families and two-parent families, though, the effects of mothers' nonstandard work schedules are associated with more internalizing behavior. We expected that single parents would experience more stress and higher levels of internalizing problems when working nonstandard schedules compared to having another reliable adult in the household to spend time with children while mothers worked. Finding that mothers' work schedules are associated with more internalizing behavior problems in two-parent families compared to single mothers living with other adults highlights the importance of examining the presence of all adults in low-income households, not just parents. If low-income fathers are relied upon to care for children while mothers work nonstandard schedules, yet their living arrangements change frequently as suggested by some research studies (Coley, 2001), it may be that this arrangement causes more stress and behavior problems. For low-income families who have more complex family arrangements, examining how both parents' work schedules as well as their attachment to families (presence and involvement) affect children is an important avenue to pursue in future research studies about parents' work schedules.

In our results for Hypothesis d, we find that the detrimental effects of nonstandard schedules on externalizing behavior are higher for girls than for boys. We do not find any significant gender differences in the effects of nonstandard schedules on internalizing or prosocial behavior. Reasons for these gender differences in externalizing behavior for low-income preschoolers are speculative. On the basis of ethnographic interviews, researchers studying the New Hope program find that low-income mothers leaving welfare for work may be more concerned about boys developing future problems and may concentrate more resources on them, such as enrollment in after-school programs (Huston et al., 2003). Our results showing greater increases in externalizing behaviors for girls than for boys when mothers work a nonstandard schedule may result from girls acting out more to get attention when their mothers' schedules are out of sync with their own. Alternatively, the mother's nonstandard schedule may lead to reduced supervision, with a greater reduction in supervision for girls than for boys, as mothers may feel that the boys require more. Finally, mothers could have higher expectations for girls' behavior and may be more likely to report when girls externalize their feelings compared to boys.

There are some limitations to the current analysis. Cross-sectional regression models do not allow us to draw precise conclusions about the causal ordering of the effects of mothers' nonstandard schedules on children's behavioral outcomes or to rule out upward or downward bias in our estimates of the negative coefficients for nonstandard work schedules because of selection. There remains the possibility that unobserved factors are correlated with both the decision to work nonstandard schedules and the negative child behavioral outcomes. By controlling for an extensive set of observed family, child, and job quality characteristics, we narrowed down the scope of error resulting from selection bias but we cannot eliminate it. In terms of causal ordering, an alternate interpretation of these results is that low-income mothers with better human capital characteristics could choose nonstandard schedules on the basis of their children's higher level of behavior problems. Given the preponderance of qualitative evidence that nonstandard schedules are not actively pursued by low-income mothers as a child-care strategy or as a family strategy to spend more time with their children (Dodson \& Bravo, 2005; Henly \& Lambert, 2005) and that our regression models control for child characteristics measured at birth that are highly correlated with future behavior 
problems, we believe that the weight of evidence supports the direction of the effects from nonstandard schedule to behavioral problems.

Another limitation is our measure of nonstandard work. Some previous studies have found the particular type of schedule (i.e., evening, night, weekend, or rotating shift) to be important for particular parental outcomes. The data for this analysis do not contain a sufficient number of cases to distinguish among the specific types of nonstandard schedules. On the basis of detailed case studies of low-wage parents' work lives that document high levels of unpredictability in the time of day and the days of week they are scheduled to work (e.g., DeParle, 2004), it is likely that even evening, night, weekend, and rotating shifts are not regularly scheduled. Therefore, low-wage workers' nonstandard schedules cannot easily be disaggregated into mutually exclusive categories. It remains to be seen whether it is useful or even appropriate to categorize low-wage workers' nonstandard schedules using traditional definitions in the most widely available national surveys, such as the Current Population Survey. A fruitful avenue for future research would involve in-depth case studies of low-income families to help formulate a better understanding of the nonstandard work schedules that low-income parents maintain.

We cannot examine the potential effects of preschoolers' child-care arrangements on behavior problems because we are unable to match children's child-care arrangements with work schedules, and we cannot detect multiple child-care arrangements. On the one hand, mothers who work nonstandard schedules often rely on informal child care with family and friends (Han, 2004), which could be detrimental for behavior because children are not exposed to prosocial developmental curricula provided in high-quality child-care centers. On the other hand, some research has shown that although low-income children on average achieve better cognitive outcomes when enrolled in high-quality center-based care settings compared to informal arrangements, these studies have found no effects on behavior problems (Loeb, Fuller, Kagan, \& Carrol, 2004). Also, low-income mothers often use multiple child-care arrangements that can include both formal and informal arrangements (Capizzano \& Adams, 2000). Mothers with very low incomes can qualify for head start programs or receive child-care subsidies if they are transitioning off of welfare so that they send their children to formal child care during the day and use informal arrangements at night or on the weekend when they work. To adequately capture the potential mediating role of child care between mothers' work schedules and behavior problems, the complexities of child-care arrangements and parents' work schedules captured in detailed time diaries are needed.

Lastly, children's behavioral outcomes and parenting stress are mother reported. Although we use well-established measures of behavior problems appropriate for preschoolers, mothers who work nonstandard schedules may report elevated levels of behavior problems if they face more parenting stress, rather than children exhibiting more behavioral problems. Including measures reported from multiple sources would help establish the severity of children's behavioral issues.

Despite these limitations, our results make an important contribution to the literature by focusing on the effects of nonstandard schedules for low-income mothers. These findings augment the small amount of existing research on the effects of work schedules on parenting and children, especially in low-income families. Our results raise concerns about low-income mothers employed in jobs that require nonstandard work hours and are consistent with a body of literature that points to family and child problems for employees who work a nonstandard schedule.

From a policy perspective, these results suggest that in the effort to move welfare recipients into the labor market, caseworkers need to be attentive to the potential parenting stressors and child behavioral problems associated with mothers working nonstandard schedules. Although research shows that in low-income families, young children of mothers who work fare better or the same as children of mothers who do not work (Zaslow \& Emig, 1997), in light of the negative associations uncovered in this study, future research should consider whether low-income mothers' employment in jobs with nonstandard schedules is better or worse for children's development in comparison to not working at all. For their part, employers in low-wage serviceoriented labor markets also should be cognizant of the issues faced by their workforce and should help design employment schedules that mitigate these potential negative consequences for families. At this time, nonstandard schedules are likely to be unfavorable work options for low-income mothers as they add stress to the 
juggling of work and family responsibilities that ultimately is associated with negative repercussions for young children.

\section{NOTE}

The authors would like to thank James Quane and three anonymous reviewers for excellent comments and Andrew Cherlin, Lisa Dodson, and Lawrence Aber for their comments on early drafts. Christopher Wimer provided exceptional research assistance. An earlier version of this article was presented at Low Income Families: Coping as Parents and Workers Conference in Washington, DC, November 2001. This research includes data collected as part of the Welfare, Children, and Families: A Three-City Study directed by Ronald Angel, Linda Burton, P. Lindsay Chase-Landsdale, Andrew Cherlin, Robert Moffitt, and William Julius Wilson. We gratefully acknowledge the support of the following organizations: National Institute of Child Health and Human Development, Office of the Assistant Secretary for Planning and Evaluation, Administration on Developmental Disabilities, Administration for Children and Families, Social Security Administration, National Institute of Mental Health, The Boston Foundation, The Annie E. Casey Foundation, The Edna McConnell Clark Foundation, The Lloyd A. Fry Foundation, Hogg Foundation for Mental Health, The Robert Wood Johnson Foundation, The Joyce Foundation, The Henry J. Kaiser Family Foundation, W. K. Kellogg Foundation, Kronkosky Charitable Foundation, The John D. and Catherine T. MacArthur Foundation, Charles Stewart Mott Foundation, The David and Lucile Packard Foundation, and Woods Fund of Chicago.

\section{REFERENCES}

Aber, J. L., \& Jones, S. M. (1997). Indicators of positive development in early childhood: Improving concepts and measures. In R.M. Hauser, B.V. Brown, \& W.R. Prosser (Eds.), Indicators of children's well-being (pp. 395 - 408). New York: Russell Sage Foundation.

Achenbach, T. M. (1991). Manual for the child behavior checklist/4-18. Burlington: University of Vermont.

Ackerman, B. P., Brown, E., \& Izard, C. E. (2003). Continuity and change in levels of externalizing behavior in school of children from economically disadvantaged families. Child Development, 74, $694-709$.

Baron, R. M., \& Kenny, D. A. (1986). The moderator-mediator variable distinction in social psychological research: Conceptual, strategic, and statistical considerations. Journal of Personality and Social Psychology, 51, 1173 - 1182.

Beers, T. M. (2000). Flexible schedules and shift work: Replacing the "9-to-5" workday? Monthly Labor Review, 123, 33 - 40.
Bogen, K. (2004). Jobs and parenting 24-7: Work schedules and parenting of the working poor. Unpublished dissertation, Johns Hopkins University, Baltimore.

Brayfield, A. (1995). Juggling jobs and kids: The impact of employment schedules on fathers' caring for children. Journal of Marriage and the Family, $57,321-333$.

Capizzano, J., \& Adams, G. (2000). The number of child care arrangements used by children under 5 . Washington, DC: Urban Institute.

Chase-Lansdale, P. L., Brooks-Gunn, J., \& Zamsky, E. S. (1994). Young African-American multigenerational families in poverty: Quality of mothering and grandmothering. Child Development, 65, $373-393$.

Cohen, J. (1988). Statistical power analysis for the behavioral sciences (2nd ed.). Hillsdale, NJ: Erlbaum.

Coley, R. L. (2001). Emerging research on lowincome, unmarried, and minority fathers. American Psychologist, 56, 743 - 753 .

Deater-Deckard, K. (2005). Parenting stress and children's development: Introduction to the special issue. Infant and Child Development, 14, 111 - 115.

DeParle, J. (2004). American dream: Three women, ten kids, and a nation's drive to end welfare. New York: Viking.

Derogatis, L. R. (2000). BSI 18 brief symptom inventory 18, administration, scoring, and procedures manual. Minneapolis, MN: NCS Pearson.

Dodson, L., \& Bravo, E. (2005). When there is no time or money: Work, family, and community lives of low-income families. In J. Heymann \& C. Beem (Eds.), Unfinished work: Building equality and democracy in an era of working families (pp. 122 - 155). New York: The New Press.

Dodson, L., \& Dickert, J. (2004). Girls' family labor in low-income households: A decade of qualitative research. Journal of Marriage and Family, 66, $318-332$.

Dunifon, R., Kalil, A., \& Bajracharya, A. (2005). Maternal working conditions and child well being in welfare-leaving families. Developmental Psychology, 41, 851-859.

Earle, A., \& Heymann, S. J. (2002). What causes job loss among former welfare recipients: The role of family health problems. Journal of the American Medical Women's Association, 57, 5 - 10.

Fenwick, R., \& Tausig, M. (2001). Family and health outcomes of shift work and schedule control. American Behavioral Scientist, 44, 1179 - 1198.

Garey, A. I. (1999). Weaving work and motherhood. Philadelphia: Temple University Press. 
Grosswald, B. (2003). Shift work and negative workto-family spillover. Journal of Sociology and Social Welfare, 29, $29-49$.

Grosswald, B. (2004). The effects of shift work on family satisfaction. Families in Society: Journal of Contemporary Social Services, 85, 413 - 423.

Hack, M., Klein, N. K., \& Taylor, H. G. (1995). Long-term developmental outcomes of low birth weight infants. Future of Children, 5, 176 - 196.

Han, W.-J. (2004). Nonstandard work schedules and child care decisions: Evidence from the NICHD study of early child care. Early Childhood Research Quarterly, 19, 231 - 256.

Han, W.-J. (2005). Maternal nonstandard work schedules and child cognitive outcomes. Child Development, 76, 137 - 154.

Han, W.-J., Waldfogel, J., \& Brooks-Gunn, J. (2001). The effects of early maternal employment on later cognitive and behavioral outcomes. Journal of Marriage and Family, 63, 336 - 354.

Hattery, A. J. (2001). Tag-team parenting: Costs and benefits of utilizing nonoverlapping shift work in families with young children. Families in Society: Journal of Contemporary Human Services, 82, $419-427$.

Henly, J. R., \& Lambert, S. E. (2005). Linking workplace practices to child care requirements: Lowerlevel workers in lower-skilled jobs. In S. M. Bianchi, L. M. Casper, K. E. Christensen, \& R. B. King (Eds.), Workforce/workplace mismatch? Work, family, health \& well-being (pp. 473 - 492). Mahwah, NJ: Erlbaum.

Hertz, R., \& Charlton, J. (1989). Making family under a shiftwork schedule: Air force security guards and their wives. Social Problems, 36, $491-$ 507.

Heymann, S. J. (2000). The widening gap: Why America's working families are in jeopardy and what can be done about it. New York: Basic Books.

Holzer, H. J., \& Stoll, M. A. (2001). Employers and welfare recipients: The effects of welfare reform in the workplace. San Francisco: Public Policy Institute of California.

Huston, A. C., Duncan, G. J., McLoyd, V. C., Crosby, D. A., Ripke, M. N., Weisner, T. S., \& Eldred, C. A. (2005). Impacts on children of a policy to promote employment and reduce poverty for low-income parents: New hope after 5 years. Developmental Psychology, 41, 902 - 918.

Huston, A. C., Miller, C., Richburg-Hayes, L., Duncan, G. J., Eldred, C. A., Weisner, T. S., Lowe, E., McLoyd, V. C., Crosby, D. A., Ripke, M. N., \& Redcross, C. (2003). New hope for families and children: Five-year results of a program to reduce and poverty and reform welfare. New York: Manpower Demonstration Research Corporation.

Imes, A. E., \& Huston, A. C. (2004, October). Gender differences in children's behavior: The influence of neighborhood characteristics and material hardship. Paper presented at the meeting of the Association for Public Policy and Management, Atlanta.

Jackson, A. P., Brooks-Gunn, J., Huang, C.-C., \& Glassman, M. (2000). Single mothers in low-wage jobs: Financial strain, parenting, and preschoolers' outcomes. Child Development, 71, 1409 - 1423.

Kalil, A., \& Ziol-Guest, K. M. (2005). Single mothers' employment dynamics and adolescent wellbeing. Child Development, 76, 196 - 211.

Levine, P. B., \& Zimmerman, D. J. (2005). Children's welfare exposure and subsequent development. Journal of Public Economics, 89, 31 - 56.

Loeb, S., Fuller, B., Kagan, S. L., \& Carrol, B. (2004). Child care in poor communities: Early learning effects of type, quality, and stability. Child Development, 75, 47 - 65.

McLanahan, S., \& Sandefur, G. (1994). Growing up with a single parent: What hurts, what helps. Cambridge, MA: Harvard University Press.

Parcel, T. L., \& Menaghan, E. G. (1994). Parents' jobs and children's lives. Hawthorne, NY: Aldine De Gruyter.

Perry-Jenkins, M., Goldberg, A., Pierce, C., \& Sayer, A. (2006). Shift work, role overload, and the transition to parenthood. Manuscript submitted for publication.

Phillips, K. R. (2002). Parent work and child well-being in low-income families (Occasional Paper Number 56). Washington, DC: Urban Institute.

Presser, H. B. (2000). Nonstandard work schedules and marital instability. Journal of Marriage and the Family, 62, 93 - 110.

Presser, H. B. (2003). Working in a 24/7 economy: Challenges for American families. New York: Russell Sage Foundation.

Presser, H. B., \& Cox, A. G. (1997). The work schedules of low-educated American women and welfare reform. Monthly Labor Review, 120, 25 - 34.

Quint, J. C., Bos, J. M., \& Polit, D. E., (1997). New chance: Final report on a comprehensive program for young mothers in poverty and their children. New York: Manpower Demonstration Research Corporation.

Richer, E., Savner, S., \& Greenberg, M. (2001). Frequently asked questions about working welfare leavers (No. 01-30). Washington, DC: Center for Law and Social Policy. 
Ruhm, C. J. (2004). Parental employment and child cognitive development. Journal of Human Resources, 39, $155-192$.

Simon, B. L. (1990). Impact of shift work on individuals and families. Families in Society: Journal of Contemporary Human Services, 71, $342-348$.

Smith, C. L., Calkins, S. D., Keane, S. P., Anastopoulos, A. D., \& Shelton, T. L. (2004). Predicting stability and change in toddler behavior problems: contributions of maternal behavior and child gender. Developmental Psychology, 40, $29-42$.
U.S. Department of Labor, Bureau of Labor Statistics. (2005). Women in the labor force: A databook (Report No. 985). Washington, DC: Government Printing Office.

White, L., \& Keith, B. (1990). The effect of shift work on the quality and stability of marital relations. Journal of Marriage and the Family, 52, 453 - 462.

Wolfe, B., \& Hill, S. (1995). The effect of health on the work effort of single mothers. Journal of Human Resources, 20, $42-62$.

Zaslow, M. A., \& Emig, C. A. (1997). When lowincome mothers go to work: Implications for children. Future of Children, 7, 110 - 115. 
Copyright of Journal of Marriage \& Family is the property of Blackwell Publishing Limited and its content may not be copied or emailed to multiple sites or posted to a listserv without the copyright holder's express written permission. However, users may print, download, or email articles for individual use. 